\section{KENTRON}

REVUE PLURIDISCIPLINAIR

DU MONDE ANTIQUE

\section{Kentron}

Revue pluridisciplinaire du monde antique

23 | 2007

La démesure (fin)

\title{
Edoarda Barra-Salzédo, En soufflant la grâce. Âmes, souffles et humeurs en Grèce ancienne
}

\section{Michelle Lacore}

\section{(2) OpenEdition}

\section{Journals}

Édition électronique

URL : http://journals.openedition.org/kentron/1760

DOI : 10.4000/kentron. 1760

ISSN : 2264-1459

Éditeur

Presses universitaires de Caen

\section{Édition imprimée}

Date de publication : 31 décembre 2007

Pagination : 199-200

ISBN : 978-2-84133-321-9

ISSN : 0765-0590

\section{Référence électronique}

Michelle Lacore, «Edoarda Barra-Salzédo, En soufflant la grâce. Âmes, souffles et humeurs en Grèce ancienne », Kentron [En ligne], 23 | 2007, mis en ligne le 16 mars 2018, consulté le 19 novembre 2020. URL : http://journals.openedition.org/kentron/1760 ; DOI : https://doi.org/10.4000/kentron.1760

\section{(c) (i) (9)}

Kentron is licensed under a Creative Commons Attribution-NonCommercial-NoDerivatives 3.0 International License. 


\section{Edoarda Barra-Salzédo, En soufflant la grâce. Âmes, souffles et humeurs en Grèce ancienne, Grenoble, Éditions Jérôme Millon (Horos), 2007, 254 p.}

Cet ouvrage sera certainement considéré comme une contribution importante et originale à l'anthropologie de la Grèce ancienne, anthropologie ici résolument matérialiste, axée sur la sexualité, choisissant pour guide une lignée très particulière de penseurs anciens, les physiologues ioniens, puis les pythagoriciens, l'école médicale hippocratique avec ses échos chez Aristote, et enfin les stoïciens, qui font de la chaleur et du souffle contenu dans les humeurs corporelles et, au plus haut point, dans la plus accomplie d'entre elles, le sperme, la source des fonctions intellectuelles et spirituelles.

L'auteur, qui se définit comme une anthropologue de bibliothèque, met sa compétence linguistique au service d'une promenade à travers des textes non seulement «scientifiques» mais aussi empruntés à la poésie épique, lyrique, dramatique, et, apparaissant comme leur suite naturelle, des pages platoniciennes consacrées à l'inspiration, illustrant l'idée d'une inspiration, d'un souffle ou de souffles qui sont la résultante de l'activité sexuelle (qu'il s'agisse d'hommes ou de dieux) et peuvent représenter l'acte érotique lui-même. Au gré de choix très personnels, une lecture originale nous est proposée, associant une érudition à la fois vaste dans les différents champs envisagés et pointue dans la discussion des textes difficiles, à une vivacité de présentation qui l'affranchit de toute pesanteur.

C'est ainsi que E. Barra réussit à ne pas défigurer, en dépit de l'optique adoptée, a priori peu littéraire et non dépourvue de provocation, la beauté des textes des poètes qui sont utilisés - et parfois longuement paraphrasés (parodos des Euménides, prophéties de Cassandre dans l'Agamemnon) - comme révélateurs des idées et des pratiques sexuelles des Grecs. L'analyse des passages retenus mobilise toute la sagacité de l'auteur pour mettre au jour, dans une civilisation pourtant réputée moins rigoriste que notre tradition marquée par un certain ascétisme chrétien, les tabous qui défendent le mystère, à la fois indicible et obscène, entourant certaines pratiques sexuelles (sexe oral, sodomie), attribuées au couple divin souverain.

Souligner les mérites de cet ouvrage ne signifie nullement que l'on adhère à la perspective proposée : nous ne serons certainement pas seule à formuler des objections et réserves de fond. L'auteur ignore délibérément un autre courant qui, depuis les origines, c'est-à-dire la poésie homérique, effectue dans les comportements humains un choix : les pratiques sexuelles extrêmes (prêtées aux divinités comme des éléments de mystère, selon des témoignages tous postérieurs à l'époque classique) sont absentes de l'évocation homérique de la sexualité, placée constamment sous le signe de la thémis, c'est-à-dire d'une norme idéale de la condition humaine, sanctionnée par les dieux, norme qui n'entre jamais dans le détail des pratiques. L'union sexuelle y est simplement définie par la belle formule: «se mélanger dans la tendresse, 
comme il est permis, normal (thémis) entre homme et femme». Homère ne s'éloigne pas de cette concision riche de sens lorsqu'il évoque Zeus lui-même saisi pour Héra d'un désir aussi puissant que lors de leur première union secrète («lorsque pour la première fois, entrés dans le même lit, ils s'étaient mélangés dans la tendresse, à l'insu de leurs parents »), alors qu'un tableau, vu par le stoïcien Chrysippe dans un temple, représentait le couple divin pratiquant le sexe oral.

Le reproche de fond que l'on peut adresser à E. Barra est son refus de toute interprétation symbolique ou métaphorique des textes retenus, conséquence d'une herméneutique réductrice qui exclut toute conception spiritualiste. Il est significatif à cet égard que l'ouvrage fondamental, quoique très ancien (1894), d'Erwin Rohde, Psyché, ne soit cité qu'une fois très brièvement (p.16 et n. 7) au début de l'ouvrage, par acquit de conscience, pour ainsi dire. Pour la première partie consacrée à Homère, l'analyse des notions voisines de psyché, thumos, aiôn, ètor, ménos ne s'appuie jamais sur l'outil philologique fondamental qu'est le Lexikon des frühgriechischen Epos. L'auteur se refuse à admettre la valeur figurée des syntagmes désignant le fonctionnement de l'âme; or, le texte homérique ne représente pas plus comme un fluide concret le ménos (l'ardeur vitale "versée » par un dieu à un guerrier) que le sommeil, également "versé» sur un personnage qu'il enveloppe. E. Barra prend délibérément au sens littéral, concret, ces expressions, puisque le souffle est selon elle le plus spirituel des éléments matériels. Nous pensons qu'il est le plus impalpable des éléments matériels, apte de ce fait à symboliser les réalités spirituelles qui échappent à l'expérience sensible, ce qui explique la remarquable convergence qui rapproche dans beaucoup de langues et de traditions l'activité spirituelle et le souffle: «le vent souffle où il veut» (Jean 3, 8). C'est ce qui apparaît dans la psyché homérique, à la fois souffle vital et free-soul.

Michelle LACORE 